\title{
SIKAP KONSUMEN TERHADAP PRODUK BUNDLING AGRIBISNIS
}

\author{
Didi Junaedi, Anton Agus Setyawan, dan Soepatini \\ Program Studi Magister Manajemen Universitas Muhammadiyah Surakarta \\ Jl. A.Yani Tromol Pos 1, Pabelan Kartusara, Surakarta 57102 \\ Email: didijuna@gmail.com
}

\begin{abstract}
The objectives of the study are how to determine product bundling strategy and implementation to Dekalb brand hybrid corn and Round-up brand herbicide. By analyzes how consumer attitudes toward buying intention in this regard farmers as buyer and retailers as products services. The data used is primary data. Primary data is obtained using 2 kind of respondents are retailers and farmers. The data obtained by distributed 30 questionnaires for retailers and 110 farmers in Grobogan. The descriptive statistic employed to analyzed data by using multiple linear regressions with $t$ test, $F$ test and coefficient of determination. The result showed that on retailers respondents attribute the product bundling has no significant influence to consumer buying intention but consumer attitudes significantly influence the buying intention. On the farmers respondents showed that attributes of the product bundling and consumer attitudes positive and significant influence to buying intention.
\end{abstract}

Keywords: Product Bundling, Attribute Product, Attitude, Intention

\begin{abstract}
Abstrak
Tujuan dari penelitian ini adalah bagaimana menentukan strategi produk bundling dan implementasi untuk Dekalb merek jagung hibrida dan Round-Up merek herbisida. Dengan menganalisa sikap konsumen bagaimana menuju membeli niat dalam ini petani menganggap sebagai pembeli dan pengecer jasa produk. Data yang digunakan adalah data primer. Data primer diperoleh dengan menggunakan 2 jenis responden pengecer dan petani. Data yang diperoleh didistribusikan 30 kuesioner untuk pengecer dan 110 petani di Grobogan. Deskriptif statistik yang digunakan untuk menganalisis data dengan menggunakan regresi linier dengan uji t, uji $\mathrm{F}$ dan koefisien determinasi. Hasil penelitian menunjukkan bahwa pada pengecer responden atribut bundling produk tidak memiliki pengaruh yang signifikan terhadap niat beli konsumen tetapi sikap konsumen berpengaruh signifikan terhadap niat beli. Pada petani responden menunjukkan bahwa atribut dari bundling produk dan sikap konsumen berpengaruh positif dan signifikan terhadap niat beli.
\end{abstract}

Kata Kunci: Bundling Produk, Atribut Produk, Sikap, Niat 


\section{Pendahuluan}

Perkembangan ragam produk tanaman jagung saat ini mengalami perkembangan dan tingkat persaingan yang pesat. Perkembangan itu telah menyebabkan pula peningkatan inovasi dalam strategi persaingan. Di mana persaingan ini dapat menjadikan setiap perusahaan perlu menerapkan suatu strategi tersendiri yang kreatif dan berbeda untuk memenangkan pasar yang ada. Sihombing (2015) mengatakan bahwa persaingan pasar diantara perusahaan-perusahaan penyedia benih jagung hibrida saat ini semakin ketat. Ada beberapa perusahaan multinasional seperti Dupont dengan merek Pioneer, Monsanto dengan merek Dekalb, Syngenta dengan merek NK, Charoen Pokphand dengan merek Bisi serta masih banyak lagi perusahaan-perusahaan nasional penyedia benih jagung hibrida lainnya yang saling mengisi pasar jagung hibrida di Indonesia.

Berdasarkan pada laporan tahunan Direktorat Jenderal Tanaman Pangan TA 2010 adalah data luas lahan tanaman jagung sebesar 4,351.579 hektar. Dimana luas lahan tersebut merupakan $71.06 \%$ adalah diisi oleh tanaman jagung dengan Varietas Produksi Tinggi (VPT). Varietas jagung berproduksi tinggi atau yang mempunyai berat pipilan kering perhektar lebih dari 7 ton seperti yang dihasilkan oleh varietas seperti P21, P27, DK77, DK85, DK888, NK33 dan NK6326.

Tujuan penelitian ini adalah mengetahui bagaimana penerapan strategi produk bundling agribisnis buatan Monsanto pada jagung hibrida merek Dekalb dan herbisida merek Round up. Serta mengetahui sikap konsumen terhadap minat beli produk dalam hal ini petani dan retailer. Dalam penelitian ini akan disajikan konsep produk bundling antara Benih jagung hibrida merek Dekalb dengan herbisida/racun rumput merek Round up. Petani umumnya menggunakan 3 liter herbisida untuk kebutuhan perhektar lahan atau setara dengan $15 \mathrm{~kg}$ kebutuhan benih jagung Hibrida. Sedangkan rata-rata kebutuhan benih jagung Hibrida dimusim hujan dilahan tegalan adalah $5 \mathrm{~kg}$ atau sama dengan 1 liter herbisida sehingga produk bundling yang terjadi adalah dengan menawarkan satu paket produk berisi 1 liter herbisida merek Round up dan $5 \mathrm{~kg}$ benih jagung hibrida merek Dekalb.

Varibel penelitian ini yaitu: (1) Bundling, Menurut Stremersch dan Tellis (2002) bundling mempunyai dua dimensi product bundling dan price bundling. Adapun indikatornya adalah waktu yang tepat untuk menawarkan produk bundling, harga yang tepat dan kemasan dari produk bundling sendiri. (2) Harga, dimensinya adalah keterjangkauan harga, kesesuaian dengan kualitas, daya saing serta kesesuaian harga dengan manfaat (Stanton, 1996). Indikatornya adalah harga bundling lebih murah dibandingkan terpisah, tidak mengurangi kualitas produk serta lebih memberikan nilai tambah. (3) Sikap Pelanggan (Attitude), menurut Peter dan Olson (1999) ada 3 dimensi yaitu kognisi, afeksi dan conation. Indikatornya adalah sikap petani terhadap merek produk yang ditawarkan, terhadap paket produknya dan bagaimana keluwesan tenaga penjual dalam menawarkannya. (4) Minat Beli (Intention), Schiffman dan Kanuk menyampaikan bahwa dimensi minat beli adalah ketertarikan mencari informasi, mempertimbangkan untuk membeli, mencoba, ingin mengetahui dan ingin memiliknya.

Pada umumnya sebelum melakukan penanaman benih para petani mempersiapkan lahan mereka dengan dibajak ataupun disemprotuntukmemastikanbahwabenihyang akan ditanam dapat tumbuh dan berkembang dengan baik. Pembajakan atau penyemprotan biasa dilakukan kurang lebih satu minggu sebelum penanaman, penyemprotan yang baik biasanya dilakukan dengan menggunakan racun rumput (herbisida) berbahan aktif glyphosat. Glyphosat dapat mengendalikan gulma ditanaman jagung dan meningkatkan pertumbuhan serta produksi tanaman jagung hibrida dilahan budidaya (Simanjuntak, 2014).

Umumnya petani melakukan penanaman benih jagung hibrida satu minggu setelah dilakukan penyemprotan racun rumput 
(herbisida) ke lahan sebagai tahapan persiapan tanam jagung. Penyemprotan dilakukan untuk mematikan gulma pada lahan tegalan ataupun sawah sehingga lahan terlihat bersih. Sifat dari bahan aktif glyfosat yang sistemik dapat mematikan gulma secara perlahan, gulma yang tidak dikendalikan akan dapat mengganggu pertumbuhan tanaman jagung nantinya. (Simanjuntak, 2014).

\section{Tinjauan Pustaka}

\section{Produk dan Bundling}

Produk menurut Kotler dan Amstrong (2006), adalah segala sesuatu yang dapat ditawarkan ke pasar untuk mendapatkan perhatian, kepemilikan, penggunaan atau konsumsi dan dapat memuaskan keinginan atau kebutuhan.

Produk Bundling, menurut Wilson, (1993) dalam Venkatesh dan Mahajan (2009), merupakan strategi marketing dua atau lebih produk atau pelayanan sebagai sebuah paket harga sebagai bentuk dari harga non linier. Hal ini sejalan dengan apa yang disampaikan oleh Derdenger dan Kumar, (2013) yang diperkuat pendapat dari Arga dalam Arifin et al (2010), dimana bundling adalah sebuah strategi pemasaran yang melibatkan penawaran dua produk atau lebih untuk dijual sebagai satu kesatuan unit jual. Biasanya, suatu harga yang diberikan dalam satu paket produk hasil bundling atau kombinasi akan mempunyai harga lebih murah dibandingkan harga per satuan produk apabila konsumen akan membelinya dengan cara satuan atau dibeli terpisah.

Perusahaan menerapkan produk bundling dalam memasarkan produknya adalah untuk memberikan sebuah daya tarik yang lebih terhadap pembeli atau pelanggan sehingga dapat memacu dan terus meningkatkan volume penjualan produk perusahaan tersebut secara keseluruhan. Selain itu dalam penelitian ini konsep produk bundling akan coba diterapkan peneliti dengan tujuan memenangkan persaingan pasar dari produk benih jagung pesaingnya.
Menurut Adams dan Yellen Xu (2009) menyampaikan bahwa terdapat dua jenis bundling yaitu, Pure Bundling, adalah penerapan strategi untuk suatu produk bundling dimana konsumen atau pembeli hanya dapat melakukan pembelian produk yang ditawarkan oleh penjual dalam satu bentuk paket produk. Dan Mixed bundling adalah suatu penerapan strategi produk bundling dimana konsumen atau pelanggan dapat melakukan pemilihan produk tersebut secara paket ataupun terpisah.

Kotler dan Keller (2005), menyapaikan bahwa pure bundling akan terjadi apabila perusahaan hanya menawarkan produkproduknya sebagai satu gabungan sedangkan dalam mixed bundling penjual menawarkan barang satuan maupun gabungan. Strategi ini sangat umum digunakan dalam suatu bisnis untuk meningkatkan penjualan. Strategi ini akan memiliki tingkat keberhasilan tinggi apabila (1). Biaya produksi rendah. (2) Pangsa pasar cukup besar. (3) Konsumen berminat karena ada unsur penyederhanaan dalam proses pembelian produk dan dapat mengambil manfaat dari pembelian produk. (4) Rata-rata marginal cost rendah. (5) Customer acquisition cost tinggi.

\section{Perceived Price dan Perceived Value}

Peter dan Olson (1999), menyampaikan bahwa perceived price adalah berkaitan dengan bagaimana informasi harga dipahami seluruhnya oleh konsumen dan memberikan makna yang dalam bagi konsumen. Suatu persepsi konsumen mengenai harga suatu produk atau pengorbanan relatif yang akan dikeluarkan untuk memperoleh suatu produk yang diinginkan dibandingkan dengan harga atau pengorbanan pada satu produk lain yang mempunyai jenis yang sama. Schiffman dan Kanuk (2008) mengemukakan bahwa bagaimana pandangan atau persepsi konsumen mengenai harga tertentu tinggi, rendah atau wajar mempunyai pengaruh yang kuat terhadap maksud membeli dan kepuasan membeli. Sedangkan perceive value adalah 
penilaian yang diberikan oleh konsumen secara menyeluruh akan manfaat dari suatu produk yang ditawarkan berdasarkan persepsi mengenai apa yang telah mereka terima dan apa yang telah mereka berikan.

\section{Perilaku Konsumen}

Peter dan Olson (1999) mendefinisikan bahwa perilaku konsumen sebagai interaksi yang dinamis antara pengaru dan kognisi, perilaku dan kejadian disekitar kita dimana manusia melakukan aspek pertukaran dalam hidupnya. Sedangkan menurut Schiffman dan Kanuk (2008), penguatan perilaku harus dilakukan para konsumen sebelum perilaku yang diinginkan didapat. Perilaku akan menampilkan pelanggan dalam melakukan pencarian, membeli, menggunakan, mengevaluasi dan membuang produk dan layanan yang mereka harapkan akan memuaskan kebutuhan mereka. Sedangkan Model Sikap Fishbein yang disampaikan Ajzen dan Fishbein (1980) dalam Vallerand et. al. (1992), pada prinsipnya akan menghitung sikap seseorang terhadap sebuah objek, yang dikenali lewat atribut-atribut yang melekat pada obyek tersebut.

\section{Sikap Konsumen dan Minat Beli.}

Menurut Schiffman dan Kanuk (2008) sikap adalah kecenderungan yang dipelajari dalam berperilaku dengan cara yang menyenangkan atau tidak menyenangkan terhadap suatu obyek tertentu. Dijelaskan bahwa karakteristik lain dari sikap adalah bahwa sikap relative konsisten dengan perilaku yang dicerminkannya tetapi walaupun mempunyai konsistensi, sikap tidak selalu harus permanen yang berarti sikap dapat berubah. Sikap konsumen dapat berubah dari satu situasi ke situasi yang lain. Pembentukan sikap konsumen sangat dipengaruhi oleh pengalaman pribadi, pengaruh anggota keluarga dan teman-teman, pemasaran langsung serta kuatnya media massa.
MenurutFishbein dan Ajzen (2004) dalam Arifn et al. (2013), intention (minat) adalah sebuah rencana seseorang akan berperilaku dari situasi tertentu dengan cara-cara tertentu baik seseorang akan melakukannya atau tidak. Adapun indikator-indikator dari minat beli dijelaskan oleh komponen dari Schiffman dan Kanuk (2000). Komponen-komponen tersebut adalah (1) Tertarik untuk mencari informasi mengenai produk. (2) Mempertimbangkan untuk membeli. (3) Tertarik untuk mencoba. (4) Ingin mengetahui produk. (5) Ingin memiliki produk.

\section{Metode Penelitian}

Metode atau jenis penelitian yang digunakan dalam penelitian ini adalah metode penelitian deskriptif. Menurut Sanusi (2011) desain penelitian deskriptif adalah desain yang disusun dalam rangka memberikan gambaran secara sistematis tentang informasi ilmiah yang berasal dari subyek atau obyek penelitian. Menurut Sekaran (2006), analisis deskriptif dipergunakan untuk menyajikan dan menganalisa data agar lebih bermakna dan komunikatif dalam menjelaskan fenomena, yaitu dengan cara menyebarkan angket kepada sejumlah responden yang dijadikan sampel penelitian.

Lokasi yang dipilih peneliti adalah sentral jagung terbesar di Jawa Tengah yaitu Kabupaten Grobogan. Obyek penelitian ini adalah petani jagung hibrida yang telah menggunakan jagung hibrida merek Dekalb dan kios pertanian sebagai penyalur benih jagung hibrida dan pestisida dimasing-masing daerah tersebut. Jumlah sampel penelitian adalah 100 petani jagung hibrida dan 30 kios pertanian sebagai koresponden yang terdiri dari 100 petani dari beberapa desa pada 3 kecamatan utama produksi jagung di Kabupaten Grobogan dan 30 kios pertanian sebagai pengecer benih jagung hibrida Dekalb dan pestisida di Kabupaten Grobogan tersebut. Tehnik pengumpulan data yaitu dengan cara 
membagikan kuesioner kepada para petani jagung hibrida Dekalb sebanyak 100 orang 30 pertanian tersebut, untuk mendapatkan data primer peneliti juga melakukan wawancara kepada responden. Skala yang digunakan adalah berdasarkan pada model skala likert digunakan untuk mendapatkan jawaban responden mengenai sikap terhadap produk bundling yang disampaikan dalam penelitian ini.

\section{Hasil Penelitian Dan Pembahasan}

\section{Uji Validitas}

Pengujian validitas dilakukan pada tiga variabel utama dalam penelitian ini, yaitu Atribut Paket Produk, Sikap Konsumen dan Minat. Metode pengujian yang digunakan untuk pengujian kuesioner responden adalah KMO Measure of Sampling Adequacy (MSA).

Tabel 1. Hasil uji validitas dengan Metode KMO MSA

\begin{tabular}{llcc}
\hline & & Retailer & Petani \\
\hline KMO $M S A$. & .778 & .854 \\
$\begin{array}{l}\text { Bartlett's Test of } \\
\text { Sphericity }\end{array}$ & Approx. Chi-Square & 306.919 & 762.231 \\
& Df & 91 & 91 \\
& Sig. & .000 & .000 \\
Keterangan & & Valid & Valid \\
\hline
\end{tabular}

Sumber: Data primer yang diolah, 2015

Nilai KMO MSA dalam pengujian kuesioner dengan responden retailer sebesar 0,778 yang berarti diatas 0,5 serta nilai Chi-Squares signifikan pada 0,000 maka disimpulkan bahwa uji tersebut valid dan dapat diteruskan. Sedangkan pengujian pada responden petani nilai KMO MSA sebesar 0,854 yang berarto lebih dari 0,5 dan Chi-Squares signifikan pada 0,000 maka uji analisis faktor valid dan dapat dilanjutkan.

\section{Uji Reliabilitas}

Untuk menguji realibilitas dalam penelitian ini digunakan rumus Alpha Cronbach. Menurut Ghozali (2001), bahwa butir tes mempunyai reliabilitas baik, jika nilai Alpha Cronbach lebih besar dari 0,6.

Tabel 2. Nilai Alpha Cronbach pada uji reliabilitas

\begin{tabular}{lcc}
\hline \multicolumn{1}{c}{ Variabel } & Retailer & Petani \\
\hline Atribut Paket Produk & 0,676 & 0,678 \\
Sikap Konsumen & 0,907 & 0,858 \\
Minat Beli & 0,906 & 0,873 \\
Keterangan & Reliabel & Reliabel \\
\hline
\end{tabular}

Sumber: Data Primer yang diolah, 2015

Dari hasil pengujian reliabilitas instrumen menunjukkan bahwa semua variabel yang diuji baik pada responden retailer maupun petani memiliki criteria nilai Cronbach's Alpha $>0,6$ sehingga dikategorikan reliabel dalam pengujian dan layak digunakan.

\section{Analisis Regresi Linier Berganda}

Analisis ini untuk mengetahui arah hubungan antara variabel independen dengan variabel dependen apakah positif atau negatif dan untuk memprediksi nilai dari variabel dependen. 
Tabel 3. Hasil uji Regresi Linier Berganda responden Retailer

\begin{tabular}{lccccc}
\hline \multirow{2}{*}{ Model } & \multicolumn{2}{c}{$\begin{array}{c}\text { Unstandardized } \\
\text { Coeficients }\end{array}$} & \multicolumn{2}{c}{ Standardized Coeficients } & \multirow{2}{*}{ Sig. } \\
\cline { 2 - 5 } & $\mathbf{B}$ & Std. Error & Beta & t-hitung & \\
\hline Konstanta & 1,542 & 2,648 & & 0,582 & 0,565 \\
Atribut Produk & 0,179 & 0,135 & 0,163 & 0,1325 & 0,196 \\
Sikap Konsumen & 0,516 & 0,087 & 0,730 & 5,945 & 0,000 \\
\hline
\end{tabular}

Sumber: Data primer yang diolah, 2015

Hasil uji linier berganda pada responden konsumen, ditunjukkan dengan persamaan retailer menunjukkan bahwa sikap konsumen regresi:

berpengaruh positif terhadap minat beli $\mathrm{Y}=1,542+0,179 \mathrm{X}_{1}+0,516 \mathrm{X}_{2}$

Tabel 4.Hasil uji Regresi Linier Berganda responden Petani

\begin{tabular}{lccccc}
\hline \multirow{2}{*}{ Model } & \multicolumn{2}{c}{$\begin{array}{c}\text { Unstandardized } \\
\text { Coeficients }\end{array}$} & \multicolumn{2}{c}{$\begin{array}{c}\text { Standardized } \\
\text { Coeficients }\end{array}$} & \multirow{2}{*}{ Sig. } \\
\cline { 2 - 5 } & B & $\begin{array}{c}\text { Std. } \\
\text { Error }\end{array}$ & Beta & t-hitung & \\
\hline Konstanta & 1,258 & 1,257 & & 1,001 & 0,319 \\
Atribut Produk & 0,139 & 0,061 & 0,148 & 2,272 & 0,25 \\
Sikap Konsumen & 0,569 & 0,052 & 0,711 & 10,929 & 0,000 \\
\hline
\end{tabular}

Sumber: Data primer yang diolah, 2015

Hasil regresi linier berganda pada responden petani menunjukkan bahwa atribut paket produk dan sikap konsumen berpengaruh positif terhadap minat beli konsumen, yang ditunjukkan dengan persamaan regresi:

$$
Y=1,258+0,139 X_{1}+0,569 X_{2}
$$

Koefisien determinasi akan menunjukan derajat pengaruh variabel yang diuji. Hasil koefisien determinasi pada responden retailer menunjukan nilai adjusted $R$ square sebesar 0,617 yang berarti bahwa pengaruh variabel atribut paket produk dan sikap konsumen sebesar $61,7 \%$ dan sisanya 38,3\% dipengaruhi oleh variabel diluar model.

Tabel 5. Hasil Koefisien Determinasi 2 responden

\begin{tabular}{ccccc}
\hline Model & R & R Square & Adjsuted R Square & Std. Error of Estimate \\
\hline \multirow{5}{*}{\begin{tabular}{c}
\multicolumn{4}{c}{ Responden Retailer } \\
\end{tabular}} & $.802^{\mathrm{a}}$ & .644 & .617 & 1.59276 \\
1 & \multicolumn{4}{c}{ Responden Petani } \\
\hline
\end{tabular}

Sumber: Data primer yang diolah, 2015

Sedangkan pada responden petani hasil koefisien determinasi menunjukkan nilai adjusted $R$ square sebesar 0,594 ini dapat diartikan bahwa determinasi variabel atribut paket produk dan sikap konsumen dalam mempengaruhi minat beli konsumen sebesar
$59,4 \%$ dan sisanya 40,6\% dipengaruhi oleh variabel diluar model.

Uji $F$ akan menunjukkan hasil uji pengaruh signifikansi bersama-sama terhadap variabel yang diuji.

Tabel 6. 


\begin{tabular}{|c|c|c|c|c|c|}
\hline \multicolumn{6}{|c|}{ Hasil uji F pada 2 Responden } \\
\hline Model & $\begin{array}{c}\text { Sum of } \\
\text { Squares }\end{array}$ & Df & $\begin{array}{c}\text { Mean } \\
\text { square }\end{array}$ & $\mathbf{F}$ & Sig. \\
\hline \multicolumn{6}{|c|}{ Responden Retailer } \\
\hline Regression & 123.804 & 2 & 61.902 & 24.401 & .000 \\
\hline Residual & 68.496 & 27 & 2.537 & & \\
\hline Total & 192.300 & 29 & & & \\
\hline \multicolumn{6}{|c|}{ Responden Petani } \\
\hline Regression & 379.548 & 2 & 189.774 & 80.640 & .000 \\
\hline Residual & 251.807 & 107 & 2.353 & & \\
\hline Total & 631.355 & 109 & & & \\
\hline
\end{tabular}

Sumber: Data primer yang diolah, 2015

Hasil uji $F$ pada responden retailer menunjukkan bahwa nilai $\mathrm{F}_{\text {hitung }}$ sebesar 24,401 sedangkan pada responden petani nilai $\mathrm{F}_{\text {hitung }}$ adalah 80,640 dengan nilai signifikansiyang sama yaitu 0,000 sehingga disimpulkan bahwa secara bersama-sama variabel atribut produk dan sikap konsumen berpengaruh positif terhadap minat beli.

Uji t digunakan untuk mengetahui tingkat signifikansi pengaruh antar masing-masing variabel.

Tabel 7. Hasil uji t pada 2 Responden

\begin{tabular}{lccc}
\hline \multicolumn{1}{c}{ Variabel } & t-hitung & t-tabel & Sig. \\
\hline \multirow{2}{*}{ Atribut Paket Produk } & Responden Retailer & & \\
Sikap Konsumen & 1,325 & 2,042 & 0,196 \\
& 5,945 & 2,042 & 0,000 \\
Atribut Paket Produk & Responden Petani & & \\
Sikap Konsumen & 2,272 & 1,984 & 0,025 \\
\hline
\end{tabular}

Sumber: Data primer yang diolah, 2015

Hasil uji $t$ pada responden retailer maupun petani menunjukkan bahwa sikap konsumen memiliki nilai $p$-value $<0,05$ dan t-hitung $>$ t-tabel sehingga didapat bahwa sikap konsumen pada responden retailer berpengaruh pada minat beli sedangkan pada responden petani sikap konsumen dan atribut produk berpengaruh pada minat beli. Variabel atribut produk pada responden retailer memiliki nilai $p$-value $>0,05$ dan nilai t-hitung $<$ t-tabel yang berarti atribut produk tidak berpengaruh pada minat beli konsumen.

\section{Penutup}

Simpulan penelitianini ada;ah atribut pada produk bundling tidak mempengaruhi secara signifikan terhadap minat jual konsumen namun sikap konsumen justru memberikan pengaruh yang signifikan terhadap minat jual retailer. Pada responden petani ditunjukkan bahwa atribut produk bundling dan sikap konsumen berpengaruh positif dan signifikan terhadap minat beli. Ini berarti bahwa petani sebagai pembeli sangat memberikan perhatian tersendiri terhadap 
atribut produk yang digunakan seperti kualitas produk yang harus tetap terjaga, harga yang menjadi lebih terjangkau dan sisi promosinya sendiri yang lebih menarik. Sikap konsumen berpengaruh secara signifikan terhadap minat beli atau minat jual ditunjukkan pada kedua responden tersebut baik responden petani maupun responden retailer. Pengaruh positif dari sikap konsumen dan atribut produk bundling terhadap minat beli ditunjukkan oleh responden pada konsumen petani.

Saran dalam penelitian ini sebagai berikut. Bagi Perusahaan PT Branita Sandhini atau Monsanto Indonesia, hasil penelitian ini dapat digunakan sebagai strategi pemasaran untuk meningkatkan persaingan pasar dengan cara penerapan strategi produk bundling yang pada akhirnya akan berdampak pada peningkatan volume penjualan. Mengingat banyaknya merek herbisida dengan bahan aktif sejenis yang berkembang di pasar maka benih jagung hibrida merek Dekalb dapat juga dipaketkan dengan herbisida merek lainnya yang berasal dari perusahaan yang berbeda atau lebih dikenal dengan comarketing strategy. Bagi akademisi penelitian ini diharapkan dapat memberikan sumbangsih pengetahuan dan pemahaman terhadap kajian teoritis khususnya di bidang ilmu yang terkait dengan strategi pemasaran melalui strategi produk bundling. Bagi peneliti berikutnya hasil penelitian ini diharapkan dapat digunakan sebagai acuan, bahan pembanding dan wawasan untuk perkembangan ilmu yang bersangkutan.

\section{Daftar Pustaka}

Arifin, S., Suharyono dan Wilopo. 2010. Pengaruh Perceived Price dan Perceived Value pada Produk Bundling terhadap Minat Beli Skripsi. Malang: Fakultas Ilmu Administrasi Universitas Brawijaya.

Derdenger, T. And Kumar, V. 2013. The Dynamic Effects of Bundling s a Product Strategy. Marketing Science Journal. Page 827-858.

Foubert, B and Gijsbrechts, E. 2007. Shopper Response to Bunlde Promotions for Package Goods American Marketing Association. Journal of Marketing Research Volume. XLIV. Page 647-662.

Harris, J. 1997. The Effects of Promotional Bundling on Consumers' Evaluations of Product Quality and Risk of Purchase. Journal in Consumer Research. Volume 24, Page 168-172.

Kotler, P dan Amstrong, G. 2006. Principles of Marketing, 11 ${ }^{\text {th }}$ Edition. New Jersey: Prentice Hall.

Kotler, P. Dan Keller, KL. 2005. Manajemen Pemasaran. Jilid 1. Edisi 12. Jakarta: Penerbit PT. Indeks,

Peter, JP dan Olson, JC. 1999. Consumer Behaviour: Perilaku Konsumen dan Strategi Pemasaran. Edisi 4. Jilid 1. Jakarta: Erlangga.

Samuel, H. 2006. "Ekspektasi Pelanggan dan Aplikasi Bauran Pemasaran Terhadap Loyalitas Pelanggan Dengan Kepuasan Pelanggan Sebagai Intervening” Jurnal Fakultas Ekonomi, Universitas Kristen Petra

Schiffman, LG. dan Kanuk, LL. 2008. Perilaku Konsumen, Edisi 7. Jakarta: PT. Indeks.

Sekaran, U. 2006. Metodologi Penelitian untuk Bisnis. Edisi 4. Buku 1. Jakarta: Salemba Empat.

Vallerand, RJ., Pelletier, L.G., Deshaies, P., Cuerrier, JP dan Mongeau, C. 1992. Ajzen and Fishbein's. "Theory of Reasoned Action as Applied to Moral Behaviour: A Confirmatory 
Analysis" Journal of Personality and Social Psychology. Volume 62, Nomor I, Halaman 98-109.

Venkatesh, R dan Vijay Mahajan, 2009. "Design and Pricing Product Bundles: A Review of Normative Guidelines and Practical Approaches," pp.232-257, Handbook of Pricing Research in Marketing, Vithala R. Rao (editor). Northampton, MA: Edward Elgar Publishing Company.

Wang, X., Sun, L., Keh, H.T. 2013. "Consumer Responses to Variety in Product Bundling: The Moderating Role of Evaluation Mode” Forthcoming IJRM Volume 30:4,

Xu, Y. 2009. "Examining The Effects of Bundling Strategies On Travellers' Value Perception and Purchase Intention of a Vacation Package" Dissertation. Kota Penerbit: submitted to The Faculty of Virginia Polytechnic Institute and State University for the degree of Doctor Philosophy in Hospitality and Tourism Management. 